\title{
DE LA EMPRESA COMO PURA FACTICIDAD A LA RELACIÓN DE TRABAJO SIN CONTRATO*
}

\author{
Claudio Palavecino Cáceres ${ }^{* *}$ \\ Universidad de Chile \\ "La única vía para dar origen a una relación jurídica laboral reconocida por el sistema del \\ Derecho del Trabajo es el contrato, que constituye la exclusiva via de obligarse en una sociedad de \\ hombres libres". \\ Juan Carlos Soto Calderón ${ }^{1}$ \\ No hay dogmática sin historia. O no debería haberla, porque los conceptos e instituciones no \\ nacen en un vacio puro e intemporal, sino en lugar y fecha conocidos y a consecuencia de procesos \\ históricos de los que arrastran una carga quizás invisible, pero condicionante". \\ Francisco Tomás y Valiente ${ }^{2}$
}

\begin{abstract}
RESUMEN: El autor comienza analizando la necesidad de un concepto de empresa en el derecho del trabajo, continúa con las distintas interpretaciones que ha dado la doctrina nacional y las implicancias de sus conclusiones. Luego, presenta los antecedentes históricos y dogmáticos de las tesis que postulan prescindir de las formas y la voluntariedad como fundamento de las relaciones jurídicas, destacando sus antecedentes totalitarios, y el iter por el que fue asumida por el laboralismo tradicional hasta el punto de convertirse en parte de las fuentes del Derecho del trabajo (principio de primacía de la realidad). Termina, advirtiendo de los peligros que acarrea servirse de estas herramientas doctrinarias para estrechar legítimos fines empresariales (comerciales y tributarios), presumiendo la mala fe o simulación fraudulenta.
\end{abstract}

Palabras clave: Empresa, Derecho del trabajo, fusión, adquisición, subcontratación, principio de primacía de la realidad, grupos de empresas, personalidad jurídica.

ABSTRACT: The authorstarts by analyzing the need for aconcept of companyinlabor law, continues withthe variousinterpretations thathave been given by thenational doctrine and the implications oftheir conclusions. Then, he presentsthe antecedents of the historical anddogmatic thesesthatpostulates to leave out the forms and the willfulness as the fundaments of the juridical relations, emphasizing itstotalitarianantecedent, and theiterfor whichwas assumed by the traditionallabor doctrineto the pointof becomingpart of the sourcesof labor law (principle ofprimacyof reality).Then, he ends warning about the dangers ofthe doctrinalusethese toolsto strengthlegitimatebusiness purposes(commercialand tax), assuming bad faith orfraudulentsimulation.

Key words: Company, labor law, fusion, adquisition, over sourcing, principle of primacy of reality, group of companies, legal personality.

\footnotetext{
Este artículo es una nueva versión, ampliada, de "El concepto de empresa y su problemática", publicado en Revista Laboral Chilena, $\mathrm{N}^{\circ} 168$, julio 2008, pp. 80-85.

** Abogado. Profesor de Derecho del Trabajo y la Seguridad Social, Facultad de Derecho, Universidad de Chile.

1 Soto, J. C. "Delitos Laborales (Parte General)", documento sin editar.

2 Tomás y Valiente, F. “Independencia judicial y garantía de los derechos fundamentales”, en: Constitución: Escritos de introducción histórica. España, Madrid: 1996.
} 


\section{EMPRESA Y DERECHO DEL TRABAJO}

No es pura casualidad que, salvo una referencia muy puntual en el Código de Comer$\mathrm{cio}^{3}$, sea el Derecho del Trabajo la única rama del ordenamiento jurídico chileno en la que pueda hallarse propiamente una definición de empresa. Y es que, no solo en Chile, sino que en todo Occidente "la peripecia histórica del Derecho del Trabajo ha estado estrechamente vinculada a la existencia de la empresa y a sus vaivenes" ${ }^{4}$.

Si quisiéramos constatar positivamente la vinculación entrañable entre legislación laboral y empresa en nuestro modelo normativo, habría que señalar que aquella se plasma básicamente en tres aspectos:

El primer lugar, en que la empresa es, por excelencia, el espacio o ámbito socioeconómico en el cual surge y despliega sus efectos el contrato de trabajo. La legislación laboral presupone que la relación trabajo-salario que vino históricamente a disciplinar es una de las relaciones de intercambio que nacen con ocasión de la organización de los factores productivos y que, por tal motivo, encuentra en esta sede, por decirlo así, su hábitat natural. GARMENDIA nos recuerda que, hasta bien avanzado el siglo XX, la legislación laboral adoptó el nombre de legislación industrial ${ }^{5}$. Una excepción sería el contrato de trabajadores domés$\operatorname{ticos}^{6}$, resabio de relaciones colaborativas preindustriales, el cual aparece regulado precisamente como un contrato especial y, en cierto modo, atipico ${ }^{7}$.

Enseguida, esta misma circunstancia que sea la empresa el medio natural del contrato de trabajo pudiera explicar que el legislador haya considerado, en varias ocasiones, como un dato relevante a la hora de determinar el ejercicio de algunas obligaciones y derechos individuales y colectivos, el tamaño de la empresa, definido por el número de trabajadores que laboran en ella ${ }^{8}$.

Finalmente, puede observarse un fenómeno de subjetivación impropia de la empresa puesto que la ley y la jurisprudencia administrativa y judicial comienzan progresivamente

\footnotetext{
El art. 166 inc. final del CCo. señala que "el que ejerce la industria de hacer transportar personas o mercaderías por sus dependientes asalariados y en vehículos propios o que se hallen a su servicio, se llama empresario de transportes, aunque algunas veces ejecute el transporte por sí mismo".

4 Garmendia, M. "La empresa y sus mutaciones desde la perspectiva del Derecho del Trabajo", en: Derecho Laboral, Fundación de Cultura Universitaria, Tomo LI - N²29, enero-marzo 2008, Montevideo, p. 35.

5 Ibid.

6 En contra, Ugarte, para quien, curiosamente, el empleador de casa particular "reúne en torno a sí todos los elementos constitutivos que de acuerdo al legislador componen una empresa laboral". UGARTE, J.L. "El concepto legal de empresa en el derecho laboral chileno: mucho ruido, pocas nueces”, en: Revista Laboral Chilena, $\mathrm{N}^{\circ}$ 98, julio 2001, p. 63.

7 Como observa Garmendia, la empresa fabril-industrial clásica fue el modelo a partir del cual se definió un perfil "típico" de relación individual de trabajo. GARMENDIA, M., op.cit. (n. 4), pp. 35-36.

8 En efecto, el CT define algunas obligaciones laborales en función del tamaño de la empresa determinado por el número de trabajadores. Así, la obligación de mantener un $85 \%$ de trabajadores de nacionalidad chilena; la obligación de mantener salas cuna; la obligación de confeccionar un reglamento interno; la obligación de crear comités paritarios; la obligación de contar con un departamento de prevención de riesgos; la determinación del porcentaje de trabajadores menores de 24 años a los cuales se les podrá descontar de sus indemnizaciones el costo de capacitación proporcionada por el empleador. Asimismo, la noción de empresa determina en gran parte el ejercicio de los derechos colectivos de los trabajadores, principalmente el derecho de sindicación (vid. art. 227 CT) y el de la negociación colectiva. En relación con este último derecho, la Constitución establece el derecho de los trabajadores a negociar "con la empresa en que laboren".
} 
a prescindir de la personalidad jurídica, atribuyendo a la empresa como pura facticidad las obligaciones del empleador laboral. En una suerte de fetichismo jurídico -síntoma inequívoco de vulgarización- se transfiere a un ente desprovisto de personalidad moral los atributos propios de los sujetos personificados.

\section{EL CONCEPTO LEGAL DE EMPRESA EN EL CÓDIGO DEL TRABAJO Y LOS INTENTOS DE CASTRACIÓN DOGMÁTICA Y LEGISLATIVA}

$\mathrm{El}$ art. $3^{\circ}$, inc. $3^{\circ}$, CT define empresa como: “...toda organización de medios personales, materiales e inmateriales, ordenados bajo una dirección, para el logro de fines económicos, sociales, culturales o benéficos, dotada de una individualidad legal determinada”. Este concepto legal es fácilmente descomponible en una dimensión material o fáctica y en una dimensión jurídica o formal.

La dimensión material o fáctica consiste en elementos o "medios" de diversa naturaleza, organizados hacia fines, también de diversa naturaleza, por una dirección unitaria (“... bajo una dirección...").

La dimensión normativa o formal corresponde a la exigencia de una "individualidad legal determinada". Elemento indispensable para que la empresa transite desde la condición de objeto negocial a la de sujeto de Derecho. Pues la empresa en cuanto mero factum (conjunción finalizada de factores productivos), es para el Derecho simplemente "cosa", objeto de explotación y tráfico por quien detente sobre ella dominio, posesión o mera tenencia. Por tanto, si se quiere subjetivar este factum será preciso separarlo de su titular y revestirlo de una determinada forma. Y, en efecto, lo usual será que la organización empresarial se enmarque en cualquiera de los diversos vehículos societarios que ofrecen el Derecho civil y el Derecho mercantil, o bien bajo las figuras asociativas sin fines de lucro (corporaciones y fundaciones) del Derecho común, formas todas ellas que darán lugar a la personalidad jurídica o moral. En principio, uno podría decir que quien actúa en el tráfico jurídico celebrando contratos, contrayendo o extinguiendo obligaciones, no es jamás la empresa en cuanto mera realidad fáctica, sino la persona jurídica que es el sujeto de derechos, a quien el ordenamiento reconoce capacidad de goce y de ejercicio de derechos subjetivos ${ }^{9}$. Y es que "para todos los efectos legales" solo puede ser empleador una "persona natural o jurídica", según la definición de "empleador" contenida en la -según parece olvidada por todos- norma del art. $3^{\circ}$ letra a) CT.

Coherentemente con nuestro régimen constitucional, el cual reconoce la propiedad privada de los medios productivos y ampara la libertad económica, corresponde al dueño o titular de la organización de factores productivos la decisión de mantenerla dentro de su patrimonio o transferirla a "una persona ficticia capaz de ejercer derechos y contraer obligaciones civiles y de ser representada judicial y extrajudicialmente" (art. 545, inc. $1^{\circ}, \mathrm{CC}$ ).

En contra, la doctrina laboral comparada sostiene que "no cabe reducir la empresa a esa área de ejercicio soberano del derecho de propiedad y de la libertad contractual"

\footnotetext{
9 Pero, en un primer paso hacia la corrupción y vulgarización de los conceptos la jurisprudencia ya reconoció, alguna vez, como individualidades jurídicas de alguna clase las simples asociaciones, comunidades y sociedades de hecho, desprovistas de personalidad moral (C. A. de Santiago, 1-08-1989).
} 
(SUPIOT) ${ }^{10}$ y que "es posible afirmar la noción de empresa más allá de las formas jurídicas que fija el empresario" (GIANIBELLI) ${ }^{11}$. Se reconoce que "la empresa abandona su corporeidad y pasa a constituirse en una entidad articuladora de transacciones [...] en un conjunto de contratos organizados [...] en una empresa virtual que no posee nada tangible y cuya única virtud consiste en su capacidad de movilizar agentes económicos" (GARMENDIA) ${ }^{12}$, pero, se afirma, obviando la contradicción patente, que la empresa puede ser reconocida "en la realidad" como pura facticidad por el órgano administrativo o judicial con independencia de su configuración formal.

En nuestro medio, la corriente juslaboralista dominante, ha planteado su inconformidad con el elemento formal de la definición legal de empresa proponiendo derechamente su eliminación, para dejar subsistente de esta manera un concepto puramente material o fáctico de empresa ${ }^{13}$. Lo que en definitiva se busca con tal modificación es dejar la determinación del concepto de empresa fuera de la ley, entregada solamente a la casuística jurisprudencial.

Ha habido dos intentos de concreción legislativa de esa propuesta. En 2001, con ocasión de la discusión de la Ley $\mathrm{N}^{\circ}$ 19.759, se debatió la supresión del concepto legal de empresa de la frase "dotada de una individualidad legal determinada". La proposición fue justificada por el Gobierno en la necesidad de establecer "la debida armonía con la aplicación del principio de primacía de la realidad, esencial en la disciplina jurídica que regula el trabajo dependiente" 14 , pero finalmente fue rechazada bajo la consideración que la distorsión y abuso de las formas jurídicas podían ser corregidos mediante el perfeccionamiento de la norma que sanciona la simulación laboral (actual art. 507 CT).

Asimismo, el proyecto, que devino en la Ley 20.123, sobre subcontratación y suministro, introducía a través del art. 183 ter, CT, una nueva definición de empresa para estos efectos, igual a la del artículo $3^{\circ} \mathrm{CT}$, pero sin el elemento formal de la individualidad legal, novedad esta que tampoco prosperó por la declaración de inconstitucionalidad formal del precepto $^{15}$. Había buenas razones, de cualquier modo, para acoger la inconstitucionalidad de fondo, ya que como advirtieran los requirentes, el concepto material de empresa "impone asociaciones forzosas, obliga a asumir relaciones laborales de terceros, prohíbe administrar

\footnotetext{
10 Citado por Gianibelli, G., "Transformaciones de la empresa y el Derecho del trabajo", en: VV.AA., Las transformaciones de la empresa en el Derecho del Trabajo. Santa Fe, Argentina: Rubinzal-Culzoni Editores, 2007, p. 803.

11 Ibid., p. 803.

12 Citado por Rosembaum, J. y CASTEllo, A. Subcontratación e intermediación laboral. Estudio de las Leyes 18.099 y 18.251. Montevideo, Uruguay: Fundación de Cultura Universitaria, 2008, p. 32.

13 Por todos, UGarte, J.L. "El debate en torno al concepto de empresa", en: La Semana Jurídica, N 325 (semana del 29 de enero al 4 de febrero de 2007), LexisNexis, p. 2.

14 Proyecto de Ley de 28 de noviembre del 2000 (2626-13), en: Historia de la Ley 19.759, del 2001, Biblioteca del Congreso Nacional, Santiago de Chile, p. 11.

15 El Tribunal Constitucional estimó que el art. 183 ter ampliaba el concepto de empresa y de esta manera también los sujetos obligados al pago de cotizaciones previsionales. Al tratarse una norma que incidía sobre materias de seguridad social, la iniciativa exclusiva respecto de ella correspondía al Presidente de la República. Sin embargo, la proposición surgió por indicación parlamentaria, lo que configuró un vicio de inconstitucionalidad en su tramitación y aprobación, y el Tribunal así lo declaró en sentencia de 21 de agosto de 2006 (Rol N 534-2006).
} 
libremente una actividad económica y suplanta la voluntad del propietario, disponiendo de sus bienes" 16 .

El 5 de septiembre de 2006 ingresó al Congreso el Proyecto de Ley 4456-13 "que establece un nuevo concepto de empresa", el cual busca también instalar un concepto material de empresa y ha sido objeto de recientes indicaciones por el Ejecutivo y un senador de la República.

Por otra parte ha habido intentos, desde la dogmática del Derecho del trabajo, de neutralizar a través de sutiles interpretaciones el elemento formal de la definición legal de empresa. En esta dirección, el profesor FRANCISCO TAPIA ${ }^{17}$ se pregunta: “QQué ha querido sancionar el legislador con dicha expresión?” y, acto seguido, él mismo se contesta que "una primera respuesta posible está dada por el reconocimiento jurídico o forma jurídica que pudiere adoptar la organización del capital, bajo las figuras contractuales conocidas, sea bajo el régimen asociativo lucrativo o bien, por las formas organizativas del Título XXXIII del Código Civil". Obviamente al profesor Tapia no le satisface esta primera interpretación del elemento formal y considera que "una segunda respuesta posible es que la identidad legal dada -en el marco del Código del Trabajo-, se dirija a su reconocimiento como una organización de recursos para ciertos fines, esto es, que sea posible determinar en relación a las relaciones jurídicas que produce...". Por consiguiente, "la identidad legal parece decir relación con la identidad reconocible del conjunto de elementos que concurren en ella, antes que a una cuestión de forma. Cada vez que se esté en presencia de recursos organizados para ciertos fines y ordenados por una dirección siendo por tanto identificables como una unidad, se tratará de una empresa”. Conforme a esta segunda lectura, para que haya empresa basta con que se conjuguen los elementos materiales de la definición legal: la individualidad legal surge de esa conjunción de modo automático. De esta manera el elemento formal queda vaciado de contenido y se transforma en mero efecto del componente material de la definición.

Por su parte, la profesora IRENE ROJAS ${ }^{18}$ niega que la empresa tenga una individualidad legal y señala, en cambio, que la individualidad legal se refiere a "la identidad de la dirección de la empresa, que, además, corresponde a la persona del empleador y a la forma en que se organiza el capital". Agrega que esta identidad legal "corresponde a la de un sujeto de derecho, es decir a una persona natural o jurídica..." Hasta ahí, la argumentación es irreprochable, pero enseguida agrega que "además [la individualidad legal] corresponderá a entidades de hecho que no tienen personalidad jurídica...”. Y, entonces, si esto último es cierto, uno se pregunta, por qué razón la empresa, en cuanto mera facticidad, no podría tener, por ejemplo al modo que lo propone el profesor TAPIA, también una individualidad legal propia, distinta de la personalidad jurídica de su titular o dueño.

\footnotetext{
16 Véase los sólidos fundamentos de los senadores requirentes, reproducidos en el propio fallo citado.

17 TAPIA, F. "El concepto de empresa y los derechos sindicales en el derecho chileno del trabajo", en: VV.AA. Estudios en homenaje al profesor William Thayer A. Santiago, Chile: Sociedad Chilena de Derecho del Trabajo y de la Seguridad Social, 1998, pp. 222-244.

18 ROJAS, I. "El peculiar concepto de empresa para efectos jurídico laborales: implicancias para la negociación colectiva", en: Ius et Praxis, Año 7 N² 2, pp. 409-422. Talca, Chile: Universidad de Talca, Facultad de Ciencias Jurídicas y Sociales, 2001.
} 
Lo cierto es que estas interpretaciones voluntaristas se estrellan contra el propio texto legal. Con todo, vamos a ver enseguida que la jurisprudencia judicial y administrativa ha procedido a neutralizar el elemento formal de la definición legal de empresa, levantando el velo de la personalidad jurídica, mediante la invocación del principio de primacía de la realidad.

\section{EVOLUCIÓN DE LA JURISPRUDENCIA: DEL CONCEPTO FORMAL AL CONCEPTO MATERIAL DE EMPRESA}

No es infrecuente que empresas surgidas de los movimientos centrífugos de la descentralización, ejecuten luego movimientos centrípetos en torno a la empresa principal. "Muchas veces el fraccionamiento del ciclo productivo implica un adelgazamiento formal pero no sustancial de la empresa, que se divide solo en el plano formal pero mantienen lazos de dependencia, control y dirección entre las distintas unidades que se crean para realizar la actividad económica"19. En los llamados grupos de empresas, las sociedades o compañías en él integradas conservan su personalidad jurídica y, por tanto, su independencia formal, pero, en los hechos, están todas sujetas a una dirección económica común y única. Esta duplicidad entre autonomía jurídica y dependencia económica otorga al grupo gran flexibilidad, permitiéndole jugar con una u otra conforme a lo que convenga en un momento dado. A veces se servirá de la unidad para superar rigideces a que puedan estar sujetas las empresas por separado; otras, convendrá aprovechar la dispersión que proporciona la autonomía jurídica para evitar las desventajas que pudiera ocasionar la consideración del grupo como una sola entidad.

En el ámbito laboral, el fenómeno de los grupos, al igual que la descentralización, plantea problemas para la determinación del sujeto empleador y para la atribución de las responsabilidades asociadas a esta condición. Si para tales efectos debe primar el dato formal de la personalidad jurídica o el dato material de la dirección unitaria, es una cuestión problemática en nuestro ordenamiento jurídico ${ }^{20}$.

En un primer momento, prima tanto en la jurisprudencia administrativa como judicial una noción formal de empresa. Se identifica la empresa con el titular de la misma: una sociedad u otra entidad dotada o no de personalidad jurídica.

Con el nuevo siglo, la jurisprudencia judicial comienza a "levantar velo de la personalidad jurídica", al detectar situaciones en que un trabajador vinculado formalmente a una sociedad empleadora presta servicios promiscuamente a otra o incluso a varias compañías de un mismo grupo, con las cuales no posee contrato laboral.

Como dicen AYLWIN y ROJAS, "la jurisprudencia de los tribunales de justicia ha reconocido los grupos de empresas en el ámbito de las relaciones individuales de trabajo y para

\footnotetext{
19 Por Rosembaum, J. y Castello, A., op. cit. (n. 12), p. 20.

20 Vid. AYlWIN, A. y RojAS, I. "Los grupos de empresas y sus efectos jurídico laborales en el derecho comparado", en: Ius et Praxis, Año 11 No $^{\circ}$, pp. 197-225. Talca, Chile: Universidad de Talca, Facultad de Ciencias Jurídicas y Sociales, 2005.
} 
efectos de atribuirles las responsabilidades empresariales en el cumplimiento de las obligaciones de trabajo" 21 .

Según los citados autores, el reconocimiento del grupo y la atribución de responsabilidades laborales se construyen en base a tres elementos esenciales:

10) El supuesto de hecho (un conjunto de sociedades relacionadas que se organizan bajo una dirección);

2o) Se determina que el grupo constituye una sola entidad (empresa) para los efectos jurídico-laborales;

$\left.3^{\circ}\right)$ Responsabilidad solidaria entre las sociedades, como consecuencia natural de la anterior constatación.

En casos análogos, pero relativos a la eficacia de derechos colectivos, la Dirección del Trabajo había sido más conservadora que los tribunales y sostuvo que eran diversas empresas a pesar de todos los indicios que manifestaban lo contrario, como es que la sociedades:

"desarrollen sus faenas en el inmueble ubicado en avenida [...] compartiendo baños, casino, patio de estacionamiento y reloj control" y resuelve que "no resulta jurídicamente procedente considerar que [...] constituyen una sola empresa para los efectos de organizaciones sindicales, por lo que los trabajadores que laboran para las dos primeras no pueden afiliarse al sindicato constituido en la última" (ORD.: N¹.157/52); o que aunque los trabajadores dependientes de [...] y [...] atiendan a los clientes de la sociedad [...] y ocupen las instalaciones de la misma [...] no resulta jurídicamente procedente que los dependientes de [...] y [...] se afilien al sindicato constituido en la sociedad [...] en cuanto se trataría de dos empresas diferentes" (ORD.: 1.750/74); o "...que algunas de las empresas citadas tienen domicilio comercial común y que existen vinculaciones entre ellas en materia de socios, de representantes legales y de administración de personal...", pero resuelve asimismo que "no resulta jurídicamente procedente que los dependientes de las empresas [...] se afilien al sindicato constituido en la empresa [...] en cuanto se trataría de empresas distintas" (ORD.:1.754/78).

Sin embargo, en un dictamen más reciente (ORD. 1281/021 de 17.03.2006), la Dirección del Trabajo estimó que los trabajadores formalmente contratados por una empresa "A", prestan servicios efectivamente bajo subordinación y dependencia de la empresa "B", debiendo esta última ser considerada su empleador para efectos laborales y, por lo tanto, los trabajadores de "A" podrían afiliarse al sindicato constituido en "B". Las circunstancias de hecho que determinaron la interpretación anterior fueron:

21 AYLWIN, A. y ROJAS, I. Los grupos de empresas en el derecho chileno -2a edición-. Santiago, Chile: Editorial LexisNexis, 2007, p. 93. 
a) Que la dirección jerárquica del proceso productivo y, por ende, de las prestaciones laborales respectivas corresponde a una persona que ejerce mando sobre diversas jefaturas y subgerencias, tanto en "A" como en "B".

b) Que la misma persona, actuando en calidad de representante, suscribe al mismo tiempo contratos y finiquitos para "A" y para "B", utilizando la misma dirección comercial.

En el mismo sentido, más recientemente, mediante ORD. N³73/010, de 24.01.2007, la Dirección del Trabajo interpretó que no existía impedimento jurídico para que los trabajadores se afilien al sindicato constituido en una empresa "X", aun cuando estaban formalmente contratados por otras razones sociales del mismo grupo, fundada en que la realidad de los hechos demostraba que "X" es la empleadora. Esto se basaba en hechos similares a los anteriores: la existencia de una gerencia general de la cual "depende jerárquicamente todo el andamiaje productivo y laboral en que se desempeñan los trabajadores" y la existencia de una única gerencia de recursos humanos "a cargo de la administración del recurso humano de todas las razones sociales" y que "administra centralizadamente toda la documentación que deriva de las relaciones laborales de todos y cada uno de los trabajadores, indistintamente por quien se encuentren contratados". Esto se sumaba al hecho que "los procesos productivos de las razones sociales fiscalizadas se encuentran ligados entre sí, toda vez que los trabajadores de las cuatro razones sociales fiscalizadas se encuentran ligados entre sí, toda vez que los trabajadores de las cuatro razones sociales fiscalizadas comparten áreas comunes de trabajo y dependen administrativa y jerárquicamente" de la empresa "X".

\section{LOS PELIGROS DEL CONCEPTO MATERIAL DE EMPRESA}

Como hemos advertido en otro lugar ${ }^{22}$, si la individualidad legal de las empresas deviene irrelevante, el riesgo es que la autoridad administrativa o judicial aplique la identidad empresa-empleador a supuestos distintos del fraude a los trabajadores. Vale decir, que se haga solidariamente responsable por obligaciones laborales y de seguridad social a empresas relacionadas, por la sola circunstancia de serlo, aunque no exista entre ellas ocupación simultánea e irregular de trabajadores ni ánimo defraudatorio de ninguna clase.

La jurisprudencia podría también ampliar la extensión del concepto todavía más allá del grupo empresarial, al punto que una hipertrofiada noción de empresa termine por fagocitar la distinción entre empresa principal, contratistas y subcontratistas. A esta consecuencia se podría llegar si los tribunales aplican únicamente el principio de unidad de dirección, sin entrar a analizar si los distintos eslabones de la cadena de subcontrataciones han o no surgido de procesos de división o filialización a partir de una sociedad matriz, o si existen o no, entre ellos, participaciones accionariales cruzadas. Y es que, aun entre empresas sin un origen, ni dueños en común, las relaciones puramente comerciales entre el empresario principal y sus contratistas y subcontratistas pueden llegar a ser de tal importancia para la subsistencia de estos últimos que se genere una verdadera jerarquía entre ellas. Como observa

22 Palavecino. C. "A propósito de los grupos empresariales y el concepto de empresa", en: La Semana Juridica, LexisNexis, No327 (semana del 12 al 18 de febrero de 2007) p. 2. 
GOERLICH "la empresa principal adquiriría un cierto poder de disposición sobre la organización de la empresa contratista o subcontratista" 23 . Podría calificarse a la cadena empresario principal, contratista, subcontratistas como una sola gran empresa a efectos laborales y la consecuencia lógica de ello sería la responsabilidad solidaria entre todos los intervinientes. Esto volvería inútiles para el empresario principal los mecanismos de atenuación de la responsabilidad solidaria que contempla la propia ley. Este fenómeno ya ha podido verificarse en la comprensión de algunos tribunales del trabajo de la relación entre franquiciante y franquiciado a efectos de la responsabilidad laboral ${ }^{24}$.

Pero acaso lo más preocupante no sea lo anterior, sino el entronizamiento de un fenómeno al que han debido hacer frente cientos de veces las altas Cortes de la República por vía de protección, a saber, el surgimiento de relaciones de trabajo por mero acto administrativo $^{25}$. En definitiva, la negación al empleador de su libertad de contratación laboral, reconocida explícitamente en el art. $19 \mathrm{~N}^{\circ} 16$ CPR. El contenido de esta garantía fue definido con sencillez y claridad paradigmáticas en el seno de la Comisión de Estudios para la Nueva Constitución, donde se dijo que "en su esencia este derecho asegura que a nadie le será impuesto un trabajo o un trabajador" 26 . Se trata, pues, de una libertad bifronte, con una cara que mira hacia el trabajador y otra al empleador.

Es bien sabido que los alcances de la libertad de contratación del trabajo solo amparan el origen de la relación laboral, lo que el profesor CARLOS POBLETE (siguiendo a FERNÁNDEZ GIL) denomina el "rol genético" del contrato de trabajo ${ }^{27}$. El contenido mismo del contrato de trabajo está determinado, en gran parte, de manera heterónoma por normas de origen diverso, principalmente por la ley, que establece obligaciones para el empleador y derechos correlativos para el trabajador, con carácter irrenunciable (art. 5 CT). Por tanto, cada

23 Goerlich, J. M. "Determinación del supuesto: la noción de contrata y subcontrata de obras y servicios", en: VV.AA. Descentralización productiva y protección del trabajo en contratas. Estudios en recuerdo de Francisco Blat Gimeno. Valencia, España: Tirant lo Blanch, 2000, p. 101.

24 Así en sentencia del Segundo Juzgado de Letras del Trabajo de Santiago de veintitrés de noviembre de dos mil diez (RIT O-2400-2010): "Los hechos asentados desde la prueba producida en el proceso, permiten establecer que más allá de la forma comercial consagrada en el contrato suscrito por las demandadas en septiembre de 2007, en la práctica, tal vinculación no ha respetado la autonomía mínima e indispensable para que el franquiciado obrara como empleador exclusivo y tercero independiente en el marco de un contrato comercial, sino que el franquiciante ha reservado para sí una posición de prevalencia en el control de la forma en que se ejecuta el contrato comercial, que nace tanto de la asimetría de poder que el mismo devela, ya en la génesis contractual, cuanto de la ejecución práctica en que se materializan potestades que incluso no expresadas en el contrato (como las de organización, control de los trabajadores) configuran aquello que la jurisprudencia superior ha definido como la figura del co empleador, en una definición progresiva de los alcances del instituto del artículo 3 del Código del Trabajo (definición del empleador), que reconoce realidades en que quienes aparecen formalmente como tales, admiten a su vera la presencia de un co contratante que excede los límites de lo que el derecho privado le permite, desde que obra ejecutando potestades reales de dirección, control y regulativas respecto de trabajadores que en las formas no le pertenecen pero que la práctica revela como propios, al punto que sus propias estrategias corporativas a su respecto los controla, los congratula y los reivindica como tales".

25 Vid. los fallos emanados de la Excma. Corte Suprema de fecha 12 de mayo de 2008, que acogen los recursos de protección deducidos por empresas mineras en contra de la Dirección del Trabajo con ocasión de la fiscalización de la ley de subcontratación, causas rol nos 887-2008, 953-2008, 1062-2008, 1063-2008, 1073-2008, 1074-2008, 1075-2008, 1076-2008.

26 Comisión de Estudio para la Nueve Constitución, sesión 199, de 7 de abril de 1976, pp. 13-17, citada en: EvANS, E. Los Derechos Constitucionales. Tomo III. -3a edición-. Santiago, Chile: Editorial Jurídica de Chile, 1999, p. 11.

27 Poblete, C. "Los roles genéticos y funcional y la crisis del contrato individual de trabajo", en: Revista Laboral Chilena, $\mathrm{N}^{\circ}$ 98, julio, 2001, pp. 85-91. 
vez que celebra un contrato de trabajo, el empleador va a quedar necesariamente obligado por la legislación laboral. La Constitución le asegura, al menos, la posibilidad de decidir si contrata o no contrata.

Sin embargo, de un tiempo a esta parte, incluso esta última hebra de libertad corre serio peligro de ser cortada por el legislador. En efecto, a algunos casos contenidos desde antaño en nuestra legislación laboral, que no pasaban de ser meras rarezas ${ }^{28}$, la Ley 20.123

28 El inciso primero del artículo $8^{\circ} \mathrm{CT}$ establece que toda prestación de servicios en los términos señalados en el artículo anterior -esto es, remunerada y bajo dependencia y subordinación del empleador- hace presumir la existencia de un contrato de trabajo. Es una presunción simplemente legal -iuris tantum-, la cual, como se sabe, admite prueba en contrario. Al efecto señala el art. 47 CC que "se permitirá probar la no existencia del hecho que legalmente se presume, aunque sean ciertos los antecedentes o circunstancias de que lo infiere la ley...”. Sin embargo, en la práctica, probada que sea la prestación de servicios personales remunerados bajo subordinación y dependencia, la presunción del art. $8^{\circ} \mathrm{CT}$ viene siendo aplicada por los tribunales como una presunción iure et de iure, aun cuando la intención común de las partes hubiere sido celebrar un contrato distinto del contrato de trabajo, puesto que para estos efectos la expresión del consentimiento carece de toda relevancia para la calificación jurídica de la situación controvertida. Tal es lo que ocurre, frecuentemente, con la celebración del llamado "contrato de honorarios" en que las partes no han querido celebrar un contrato de trabajo, sino uno de naturaleza civil (técnicamente arrendamiento de servicios). Las partes han incurrido en un error que recae sobre la especie del contrato celebrado (error esencial u obstativo) que, de conformidad al art. $1453 \mathrm{CC}$ vicia (en rigor, impide) el consentimiento y debería generar la nulidad absoluta (en rigor, inexistencia) del contrato y la declaración oficiosa de la misma por el juez, conforme los arts. 1682 y 1683 CC.

Una segunda hipótesis de relación de trabajo sin contrato, puede plantearse con ocasión de la norma contenida en el inciso primero del art. $4^{\circ} \mathrm{CT}$, conforme a la cual "se presumirá de derecho que representa al empleador y que en tal carácter obliga a éste con los trabajadores, el gerente, el administrador, el capitán de barco y, en general, la persona que ejerce habitualmente funciones de dirección o administración por cuenta o representación de una persona natural o jurídica”. Este presunción puede también dar lugar a situaciones en que el empleador resulta obligado sin, o contra, su voluntad, toda vez que en incluso en caso de extralimitación o violación de prohibición expresa de su gerente o administrador no podrá desligarse de los actos o contratos realizados por éste invocando una inoponibilidad de fondo por falta de concurrencia, puesto que la presunción de derecho establecida en la ley laboral torna inoperante para estos efectos la excepción del Derecho común res inter alios acta. Finalmente, el CT contiene dos casos de cesión de contrato forzada, en que terceros pueden llegar a convertirse en empleadores sin que, necesariamente, hubieren consentido en ello y aun contra su voluntad. El art. $4^{\circ}$, inciso segundo, prescribe que "las modificaciones totales o parciales relativas al dominio, posesión o mera tenencia de la empresa no alterarán los derechos y obligaciones de los trabajadores emanados de sus contratos individuales o de los instrumentos colectivos de trabajo, que mantendrán su vigencia y continuidad con el o los nuevos empleadores". Por consiguiente, el tercero al cual se transfiere total o parcialmente el dominio, posesión o mera tenencia de la empresa, se convierte por esa mera circunstancia en nuevo empleador de los trabajadores sin que sea menester alguna expresión de voluntad de parte de aquel ni de parte de estos. No se me escapa, sin embargo, que, en general, si la empresa está dotada de personalidad jurídica -lo que ocurrirá siempre que se organice como sociedad o como corporación o fundación- no habrá propiamente cesión de contrato porque, no obstante el cambio de dominio, posesión o mera tenencia de los elementos materiales de la empresa, el empleador seguirá siendo el mismo, a saber, la persona jurídica con la cual originalmente contrataron los trabajadores. Con todo, en procesos de división, absorción, fusión societarios, producto de los cuales haya aparición de nuevas, o desaparición de antiguas, personas jurídicas, habrá propiamente cesión del contrato de trabajo entre ellas.

La otra situación la prevé el art. 184 CT, a propósito del contrato de trabajadores de casa particular. Dispone el precepto citado que "al fallecimiento del jefe de hogar, el contrato subsistirá con los parientes que hayan vivido en la casa de aquél y continúen viviendo en ella después de su muerte, los que serán solidariamente responsables del cumplimiento de las obligaciones emanadas del contrato". Tal como en el caso anterior, la ley transfiere la situación obligacional de una de las partes de la relación jurídica a terceros, sin tener en cuenta, para nada, sus voluntades. Cabe advertir, sin embargo, que no habrá en rigor cesión forzada del contrato de trabajo cuando los parientes a que alude la norma sean, a la vez, herederos del empleador, puesto que, conforme a las reglas generales de la sucesión por causa de muerte, representan a la persona del causante en todos sus derechos y obligaciones transmisibles. Por consiguiente, en tal caso, la transmisión de la posición contractual será un efecto propio de la sucesión a título universal antes que de la norma analizada, como sucede, por cierto, en la generalidad de los casos cuando fallece el empleador, puesto que dicha circunstancia no es causal de término de la relación laboral. Un análisis detallado de la cesión de contrato en Ríos, S. "Las cesiones legales de contrato. Una contribución al régimen de la cesión convencional de contrato", en: Mantilla, F. y PiZarro, C. (coord.). Estudios de Derecho Privado en homenaje a Christian Larroumet. Santiago, Chile: Fundación Fernando Fueyo Laneri, 2008, pp. 169-197. 
(sobre subcontratación y suministro de trabajadores) añadió una serie de nuevos supuestos en los cuales el contrato de trabajo surge con total prescindencia de la voluntad jurídiconegocial de las partes, por la mera ocurrencia de una situación de hecho predefinida en la ley ${ }^{29}$. Se ha producido de esta manera la tardía recepción en el Derecho del trabajo chileno de una categoría jurídica harto inquietante. Me refiero al "contrato fáctico".

\section{LAS FUENTES ENVENENADAS DE LA RELACIÓN DE TRABAJO SIN CONTRATO Y DEL PRINCIPIO DE PRIMACÍA DE LA REALIDAD}

Como nos recuerda HATTENAHUER ${ }^{30}$, la doctrina de la autonomía de la voluntad resultaba sospechosa tanto para los socialistas de Weimar como para los socialistas nacionalistas de la Alemania hitleriana ${ }^{31}$. Debía, por tanto, quedar constreñida al espacio que le concediera provisoriamente el Estado antes de ser expulsada por completo del tráfico jurídico. En 1935, KARL LARENZ definió el contrato como "una relación jurídica integrada en el orden general de la nación, cuya configuración dependía en primer término de dicho orden y, solo después, de la determinación de las partes interesadas" 32 . Por las mismas fechas y ante el incremento de negocios jurídicos decretados y configurados en su contenido por el Estado, precisamente un laboralista, NIPPERDEY introdujo la categoría del contrato forzoso ${ }^{33}$. Sin embargo, el paso decisivo lo dio, en 1941, GÜNTER HAUPT, con su ensayo Entorno a las relaciones contractuales fácticas, observando que "éstas no se basan en la conclusión de un contrato, sino únicamente en precedentes factuales" 34 .

En el ámbito del Derecho del trabajo, se produce una regresión al Derecho germánico, a la Treudienst verhältnis, Treueverhältnis o relación de servicio fiel existente entre el caudillo y su séquito. Esta relación no surgía de un acuerdo o pacto entre Führer und Gefolgschaft (conductor y conducidos) sino de un juramento del germano a los dioses (Treue). Como explica HaTtenHaUeR:

\footnotetext{
29 Así el trabajador transitorio pasará, ipso iure, a ser trabajador de la empresa usuaria cuando falte contrato escrito de puesta a disposición entre ésta y la EST; cuando celebre contrato de puesta a disposición por causales prohibidas; cuando el trabajador transitorio continúe prestando servicios para ella expirado el plazo del contrato de puesta a disposición; cuando hubiere contratado al trabajador transitorio en supuestos distintos a los autorizados; cuando se determine que el contrato tenía por objeto encubrir relación laboral permanente o bien cuando contratare trabajador de servicios temporarios por intermedio de empresas no inscritas como EST.

30 Hattenhauer, H. Conceptos fundamentales del Derecho Civil. Introducción histórico-dogmática. Barcelona, España: Editorial Ariel, 1987, p. 74. Véase también, del mismo autor, Los Fundamentos Histórico-Ideológicos del Derecho Alemán. Entre la jerarquia y la democracia. -2a edición-. Madrid, España: Derecho Reunidas, 1981.

31 Maravall, también ha observado que "el Derecho del trabajo alemán, tanto el que nace con la Constitución de Weimar como el que debió su origen a la Ordenanza del Trabajo nacional, tienen estrechas concomitancias que no se pueden negar, solamente difieren en el principio político inspirador, pero en sus lineamientos técnicos son muy parecidos”. MARAVALL, H. "Aspectos de la problemática actual del derecho del trabajo en Europa", p. 41 (sin fecha). Documento obtenido de: http:// www.cepc.es/rap/Publicaciones/Revistas/10/RPS_012_031.pdf (Consultado el 10 de noviembre de 2011).

32 Citado por Hattenhauer, H. "Conceptos... (n. 30), p. 74.

33 Ibid.

34 Citado por Hattenhauer, H. “Conceptos... (n. 30), p. 73.
} 
"El juramento no era un contrato. La estabilidad del orden jurídico no descansaba en las promesas de los usuarios del Derecho, sino en el poder de la divinidad. No importaba cómo ni por qué se había jurado; bastaba la mera ejecución de la fórmula mágica para que resultara una obligación legal. Las fórmulas y lo gestual eran decisivos por sí mismos. [...] Resultaba irrelevante jurar bajo coacción o erróneamente, o que el juramento provocase un resultado inmoral. Lo determinante para que se desencadenara el efecto automático del juramento era pronunciar textualmente la fórmula del juramento con el contenido gestual preestablecido" 35 .

El Derecho germánico, al dar supremacía a lo externo, a lo fáctico, a "la realidad", ofrecía a los juristas nazis presupuestos teóricos de irreprochable pureza a partir de los cuales desterrar por completo del ámbito laboral la autonomía de la voluntad, noción esta demasiado meridional, demasiado francesa, demasiado "subjetiva" para el gusto de la época. WOLFGANG SieBERT elaboró su teoría de la Arbeitsverhältnis (relación de trabajo), cuyo nacimiento "se desligaba por completo de la voluntad de las partes, convirtiéndola en una situación fáctica social anterior a la voluntad privada" 36 .

“...el pensamiento fundamental de la teoría de Siebert [...] es el de establecer la incorporación de a la comunidad de producción -Eingliederung in die Betriebs gemeinschaft- como fundamento de la relación de trabajo. Siendo metodológicamente necesario destruir el contrato de trabajo tradicional para llegar a la plena formulación de la doctrina de la relación de trabajo, Siebert considera "que sería puramente formal y sin ningún valor práctico designar la relación de trabajo como un contrato en la acepción o sentido del término en el Derecho civil" 37.

Para Siebert, la relación de trabajo no es, pues, una relación obligacional nacida de un acuerdo de voluntades, sino una relación de ocupación o empleo en la que la situación se origina y determina por una situación de hecho, a saber, la incorporación del trabajador a la comunidad de trabajo, independientemente de que exista o no una obligación de prestar trabajo.

La teoría de la Arbeitsverhältnis tuvo un ardoroso defensor en el juslaboralista mexicano MARIO DE LA CUEVA, quien elaboró su particular versión de la misma, el "contratorealidad" que "existe, no en el acuerdo de voluntades, sino en la realidad de la prestación del servicio y porque es el hecho mismo del trabajo y no el acuerdo de voluntades, lo que determina su existencia" 38 .

\footnotetext{
35 Ibid., p. 64.

36 Ibid., p. 92.

37 SUÁREZ, F. "El origen contractual de la relación jurídica de trabajo”, p. 74. Documento obtenido desde: http://www.cepc. es/rap/Publicaciones/Revistas/10/RPS_048_069.pdf (Consultado el 10 de noviembre de 2011).

38 De la Cueva, M. Derecho Mexicano del Trabajo. Tomo I. -11 1a edición-. México: Editorial Porrúa, p. 459. Es interesante advertir la influencia de la teoría de De la Cueva en la configuración del llamado "principio de primacía de la realidad" por el jurista uruguayo Américo Plá. (véase PLÁ, A. Los principios del derecho del trabajo -3a edición actualizada-. Buenos Aires, Argentina: Editorial Depalma, 1998, pp. 313 y ss.).
} 
Pero, salvo esta excepción, tras la caída del nazismo la teoría de la relación de trabajo quedó desacreditada, cuando menos en el ámbito iberoamericano ${ }^{39}$. No así el anticontractualismo, ni la mística corporativista de la "comunidad empresarial", que hallaron nuevo cauce, esta vez, en una fórmula ideológica aparentemente más presentable que la de SIEBERT $^{40}$ y, para mejor, francesa: la teoría de la institución de MAURICE HAURIOU. Fue PAUL DURAND quien proyectó la teoría institucionalista a la explicación de la naturaleza jurídica de la empresa, concibiendo esta como una colectividad jerarquizada que conjuga solidariamente los intereses del jefe -empresario- y de los trabajadores. Bajo este enfoque, "los elementos humanos, sumados a los materiales, dan origen a un conjunto orgánico que busca alcanzar una finalidad, consistente en la obtención del provecho mediante el ejercicio de una actividad económica determinada" ${ }^{41}$. De forma parecida a la teoría alemana, la pertenencia a la institución se produce por la integración real del sujeto, por el ejercicio de los deberes y funciones propios que le corresponden dentro de la colectividad. El propio DURAND observó la congruencia de la concepción de la relación de trabajo con su concepción de la empresa como institución, agregando que "aucun obstacle grave n'empêche la transposition, en droit Française, des principes sur lesquels repose la théorie de la relation de travail"ł2.

Me he permitido esta brevísima incursión por la genealogía del contrato de trabajo fáctico, para llamar la atención sobre el contexto en que surge la idea de relación de trabajo sin contrato y la pulsión ideológica, evidentemente totalitaria, a la que obedece y cómo, además, dicha teoría se vincula íntimamente con los conceptos organicistas-institucionalistas de la empresa.

Tampoco estaría de más recordar que esta concepción de la empresa aparece reconocida normativamente en Chile en el DL 1.006 de 1975 (Estatuto Social de la Empresa) y en el Acta Constitucional $N^{\circ} 3$ de 1976, cuando todavía gozaban de cierta influencia dentro del Régimen Militar algunos ideólogos simpatizantes del corporativismo franquista, por cierto a esas alturas superado hacía tiempo en la propia España ${ }^{43}$ y que, afortunadamente, fue barrido por el Plan Laboral.

\footnotetext{
39 En Alemania estas teorías sobrevivirían todavía 20 años al hundimiento del nacionalsocialismo. Véase, HATTENHAUER, H. "Conceptos... (n. 30), p. 92.

40 Solo aparentemente ya que como observa Maravall, por entonces "la ciencia jurídica francesa, en materia laboral, experimenta una recepción de doctrinas alemanas, lo que resulta de fácil observación al utilizar los manuales de Durand, Rouast, Durand-Vitu-Jaussaud, etcétera.; no es tan solo la preferencia en el manejo de la literatura jurídica alemana, sino la germanización de sus ideas, especialmente las teorías de la empresa laboral, el poder disciplinario del empresario, la intervención estatal, su fundamentación, como una necesidad de la organización política moderna, etc.”. MARAVALL, H., op. cit. (n. 31), p. 36. La misma poderosa influencia de las doctrinas laboralistas alemanas se observa en DURAND, Birk, R. "Labor law scholarship in France, Germany, and Italy: some remarks on a difficult question”, en: Comparative labor law and policy journal, vol. 23, № 3, p. $685,2002$.

41 Garmendia, M., op. cit. (n. 4), p. 43

42 Citado por Jeammaud, A. "La centralite retrouvée du contrat de travail en Droit française.", p. 417. Documento obtenido desde: http://www.bibliojuridica.org/libros/3/1090/24.pdf (Consultado el 11 de noviembre de 2011).

43 Véase al respecto, Colorado, I. "El nacional-sindicalismo en la España franquista. La creación de una ficción”, en Sistema, $\mathrm{N}^{\circ} 189$, noviembre, pp. 73 y ss. Madrid, 2005.
} 


\section{EL LEVANTAMIENTO DEL VELO CORPORATIVO DENTRO DE SUS JUSTOS LÍMITES: LOS FRAUDES CONTRA LOS TRABAJADORES DEL ARTÍCULO 507 CT}

Conviene tener presente, en primer lugar, que las reestructuraciones societarias buscan fines muy distintos al fraude laboral. En efecto, los procesos de división, filialización u otras formas de dispersión societarios obedecen casi siempre a optimizaciones operativas y/o tributarias de las empresas y, en general, a motivos totalmente legítimos y ajenos a lo laboral.

Desde luego que hay excepciones, pero nuestro ordenamiento jurídico contiene las herramientas para sancionar drásticamente cualquier simulación o subterfugio en perjuicio de los trabajadores en el art. 507 CT. Es aquí, precisamente, donde el legislador ha establecido el levantamiento del velo corporativo. A saber, cuando se constata en sede judicial un fraude, vale decir, una apariencia diseñada por el empleador con el fin de ocultar su persona o patrimonio para evadir sus obligaciones laborales y previsionales. Este es el único supuesto en que la ley laboral autoriza al juez para rasgar las formas jurídicas y pesquisar la configuración material de las relaciones comprometidas.

Es completamente falsa, por tanto, la extendida idea de que es imprescindible reformar el concepto de empresa para terminar con el uso abusivo de la personalidad jurídica.

\section{BIBLIOGRAFÍA}

AYLWIn, A. y ROJAS, I. Los grupos de empresas en el derecho chileno. -2a edición-. Santiago, Chile: Editorial LexisNexis, 2007.

AYLWIn, A. y ROJAS, I. "Los grupos de empresas y sus efectos jurídico laborales en el derecho comparado", en: Ius et Praxis, Año $11 \mathrm{~N}^{\circ}$ 2, pp. 197-225. Talca, Chile: Universidad de Talca, Facultad de Ciencias Jurídicas y Sociales, 2005.

Colorado, I. "El nacional-sindicalismo en la España franquista. La creación de una ficción”, en Sistema, N 189, noviembre. Madrid, 2005.

De la Cueva, M. Derecho Mexicano del Trabajo. Tomo I. -11 a edición-. México: Editorial Porrúa.

DURAND, Birk, R. "Labor law scholarship in France, Germany, and Italy: some remarks on a difficult question", en: Comparative labor law and policy journal, vol. 23, No 3, 2002.

Evans, E. Los Derechos Constitucionales. Tomo III. -3a edición-. Santiago, Chile: Editorial Jurídica de Chile, 1999.

GARMEndia, M. "La empresa y sus mutaciones desde la perspectiva del Derecho del Trabajo", en: Derecho Laboral, Fundación de Cultura Universitaria, Tomo LI - N²29, enero-marzo 2008, Montevideo.

GiAnibelLi, G., “Transformaciones de la empresa y el Derecho del trabajo”. En: VV.AA., Las transformaciones de la empresa en el Derecho del Trabajo. Santa Fe, Argentina: Rubinzal-Culzoni Editores, 2007.

GoerliCH, J. M. "Determinación del supuesto: la noción de contrata y subcontrata de obras y servicios", en: VV.AA. Descentralización productiva y protección del trabajo en contratas. Estudios en recuerdo de Francisco Blat Gimeno. Valencia, España: Tirant lo Blanch, 2000.

Hattenhauer, H. Conceptos fundamentales del Derecho Civil. Introducción histórico-dogmática. Barcelona, España: Editorial Ariel, 1987.

Hattenhauer, H. Los Fundamentos Histórico-Ideológicos del Derecho Alemán. Entre la jerarquía y la democracia. -2a edición-. Madrid, España: Derecho Reunidas, 1981. 
JEAmmaud, A. "La centralite retrouvée du contrat de travail en Droit française". Documento obtenido desde: http://www.bibliojuridica.org/libros/3/1090/24.pdf (Consultado el 11 de noviembre de 2011).

Maravall, H. "Aspectos de la problemática actual del derecho del trabajo en Europa”, p. 41 (sin fecha). Documento obtenido de: http:/www.cepc.es/rap/Publicaciones/Revistas/10/RPS_012_031.pdf (Consultado el 10 de noviembre de 2011).

PAlaVecino. C. "A propósito de los grupos empresariales y el concepto de empresa”, en: La Semana Jurídica, LexisNexis, $N^{\circ} 327$ (semana del 12 al 18 de febrero de 2007).

PLÁ, A. Los principios del derecho del trabajo -3a edición actualizada-. Buenos Aires, Argentina: Editorial Depalma, 1998.

Poblete, C. "Los roles genéticos y funcional y la crisis del contrato individual de trabajo", en: Revista Laboral Chilena, $\mathrm{N}^{\circ} 98$, julio, 2001, pp. 85-91.

Ríos, S. "Las cesiones legales de contrato. Una contribución al régimen de la cesión convencional de contrato". En: Mantilla, F. y Pizarro, C. (coord.). Estudios de Derecho Privado en homenaje a Christian Larroumet. Santiago, Chile: Fundación Fernando Fueyo Laneri, 2008, pp. 169-197.

ROJAS, I. "El peculiar concepto de empresa para efectos jurídico laborales: implicancias para la negociación colectiva”, en: Ius et Praxis, Año $7 \mathrm{~N}^{\circ}$ 2, pp. 409-422. Talca, Chile: Universidad de Talca, Facultad de Ciencias Jurídicas y Sociales, 2001.

Rosembaum, J. y Castello, A. Subcontratación e intermediación laboral. Estudio de las Leyes 18.099 y 18.251. Montevideo, Uruguay: Fundación de Cultura Universitaria, 2008.

SUÁREZ, F. "El origen contractual de la relación jurídica de trabajo". Documento obtenido desde: http://www. cepc.es/rap/Publicaciones/Revistas/10/RPS_048_069.pdf (Consultado el 10 de noviembre de 2011).

TAPIA, F. "El concepto de empresa y los derechos sindicales en el derecho chileno del trabajo", en: VV.AA. Estudios en homenaje al profesor William Thayer A. Santiago, Chile: Sociedad Chilena de Derecho del Trabajo y de la Seguridad Social, 1998, pp. 222-244.

UGARTE, J.L. "El concepto legal de empresa en el derecho laboral chileno: mucho ruido, pocas nueces", en: Revista Laboral Chilena, $\mathrm{N}^{\circ} 98$, julio 2001.

UGARTE, J.L. "El debate en torno al concepto de empresa", en: La Semana Jurídica, N³25 (semana del 29 de enero al 4 de febrero de 2007), LexisNexis. 


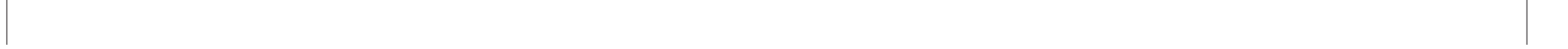

